\title{
Green Electricity from Alpine Hydropower Plants
}

Bernhard Truffer

Jochen Markard

Christine Bratrich

Bernhard Wehrli
Hydropower is a renewable source of energy of which ecological benefits include very low average greenhouse gas emissions. As a result of dams, however, more than $20 \%$ of all freshwater fish species are now considered threatened or endangered. Such negative ecological impacts are a focus of broad public concern in Alpine regions where hydropower production is most intense. The liberalization of electricity markets now provides an economic rationale for selling hydropower as green energy. This offers an opportunity to improve the ecological performance of hydropower plants. The lessons learned from this large-scale economic and

\section{Hydropower and energy production}

According to a recent review by Gleick (1998), almost $500,000 \mathrm{~km}^{2}$ of land are inundated worldwide by reservoirs. This is an area greater than the surface area of the Caspian Sea $\left(374,000 \mathrm{~km}^{2}\right)$. Most of the dams in mountain regions are used to produce hydropower. In some mountain areas of the world, river systems are almost completely dammed. Switzerland, Austria, Norway, and Japan have the highest hydroelectricity production per surface area in the world (Table 1). This high density of power plants may restrict development of tourism. In Switzerland, about $80 \%$ of Alpine river reaches are influenced by hydropower operations. Water diversion has drastically reduced the number of attractive rapids and waterfalls in the Alps (Figure 1). Of the 109 major rivers in Japan, only the Nagara has not been dammed so far.

\section{Liberalization of electricity markets}

Liberalization of electricity markets has a considerable impact on the economics of hydropower plants and projects in most countries of the world. As a technology with high capital costs and usually longterm amortization, hydropower faces the

FIGURE 1 Hydropower production in the European AIps has altered the hydrological regime of most mountain streams. This waterfall in the Schmuér catchment of the Rhine River (Switzerland) disappeared in the 1980s after the construction of a hydropower plant. (Photo by $B$. Wehrli) ecological experiment in the industrialized world might be important in other mountain regions where hydropower production is being developed or needs ecological upgrading. As a step in this direction, the present paper gives an overview of recent developments in Europe concerned with the ecolabeling of hydropower. Different initiatives for green hydropower in liberalized electricity markets are discussed, followed by analysis of the shortcomings of simplistic ecolabels. Finally, a new method for ecological assessment of green hydropower plants is outlined. This is currently being implemented in Switzerland along with ecolabeling.

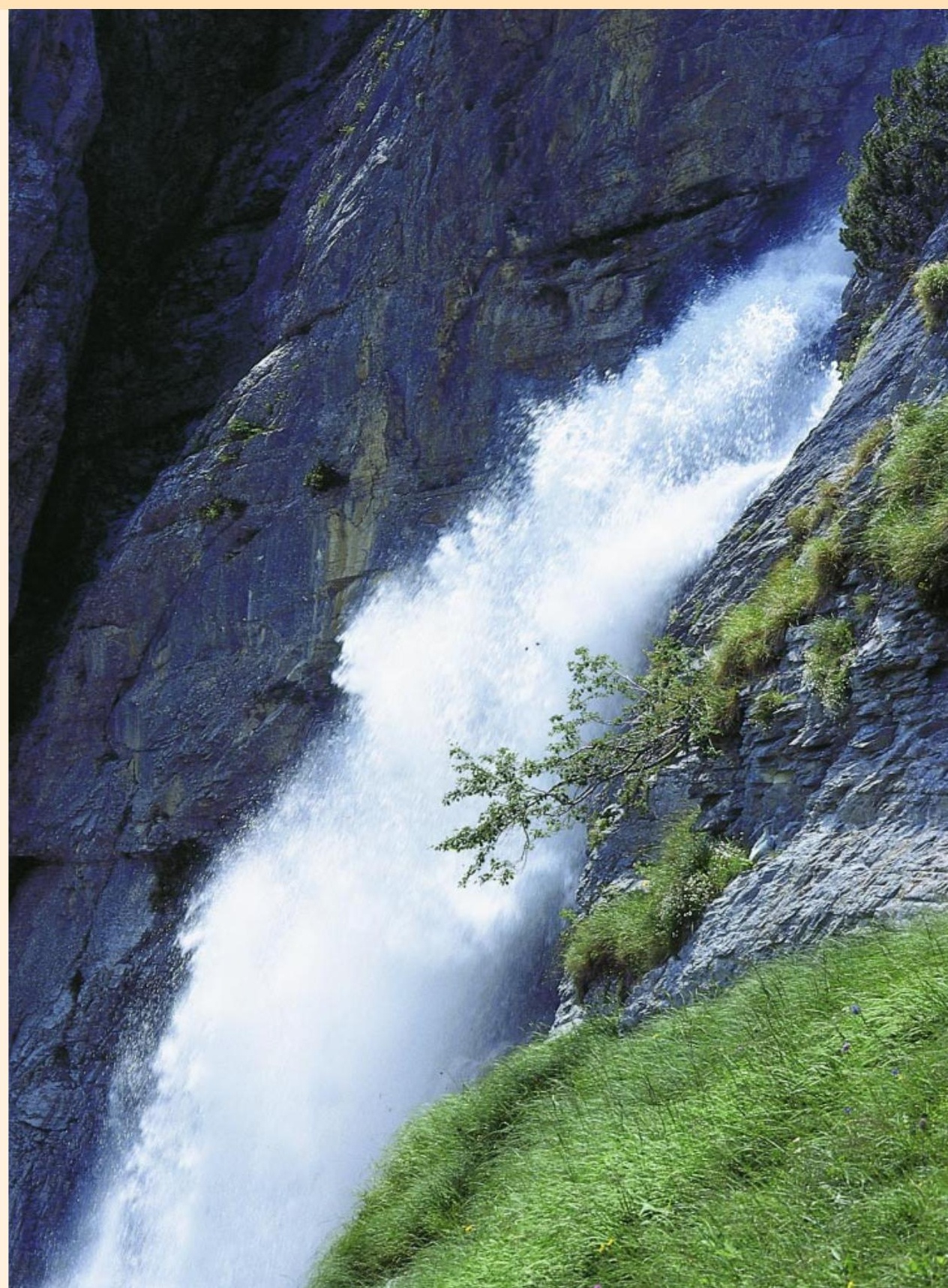


TABLE 1 Specific hydroelectric production per surface area $\left(\mathrm{Wh} / \mathrm{m}^{2} / \mathrm{y}\right)$ in the 23 countries with the highest levels of production (more than 20 terawatt-hours per year in 1996). (Source: Gleick (1998)) challenge of improving its competitive position. As an alternative strategy to cost leadership, market differentiation of products is emerging as a promising concept for liberalized markets. Generally, consumers are willing to pay more for a product that has properties they value more highly than those in a standard product. As a matter of fact, green power products have found a positive response in several electricity markets in the past decade. Due to very favorable life-cycle characteristics, hydropower is a prime candidate for delivering electricity to environmentally conscious consumers. Still, many hydropower plants have been criticized for severe local impacts on communities, landscapes, and

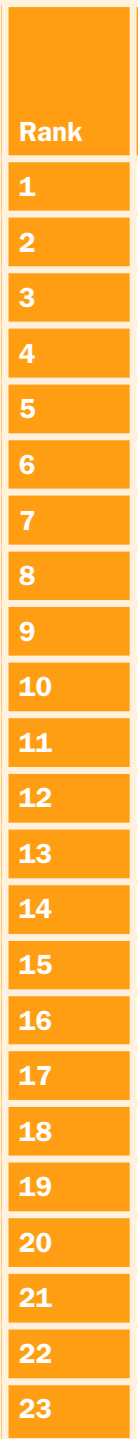

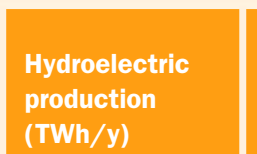

Country

Switzerland

Austria

Norway

Japan

North Korea

Sweden

Italy

France

New Zealand

Paraguay

Venezuela

Spain

Turkey

Canada

United States

Brazil

Pakistan

Colombia

India

China

Mexico

Argentina

Russian Federation

\section{6}

39

113

91

24

64

41

66

24

29

63

32

36

331

296

250

23

32

72

167

26

30

163

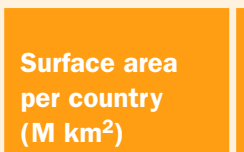

0.04

0.08

0.39

0.38

0.12

0.45

0.30

0.55

0.27

0.41

0.91

0.50

0.78

9.98

9.37

8.51

0.80

1.14

3.29

9.60

1.96

2.79

17.08
Specific

hydroelectric

production

$\left(\mathrm{W} / \mathrm{m}^{2} / \mathrm{y}\right)$

862

465

291

242

199

141

138

119

90

71

69

63

46

33

32

29

29

28

22

17

13

11

10 ecosystems. These criticisms have created a negative image, especially in countries that use hydropower intensely (Table 1). Consumers who are responsive to green electricity usually share concerns about the environmental impacts of hydropower production. Therefore, marketing of green hydropower will only be possible if its negative environmental impacts are minimized.

\section{Marketing of green electricity}

Green electricity has become available on several national electricity markets in the past decade. Initially conceived as a novel way of supporting renewable energy, it was later offered increasingly to customers as an environmentally preferable way to meet demand for electricity. Power producers and suppliers have the opportunity to position themselves as innovative and future-oriented actors while establishing stable, profitable sales of green electricity on a medium-term basis.

The key element that characterizes a green power product is its improved environmental performance in comparison with conventional power. Individual consumers expect green power to make electricity more environmentally friendly, while businesses are interested in improving their environmental image. In both cases, a particular green power product needs a good public reputation and must demonstrate additional environmental effects. However, customers need assistance in evaluating different products and may even ask for concrete purchasing recommendations. Ecolabeling is one important mechanism for enhancing transparency and providing guidelines for both marketers and customers. Ecolabels are usually designed and operated by an external, independent organization. The label may be endorsed by public authorities, environmental organizations, or consumer associations.

\section{Product declarations and ecolabels for green hydropower}

Green electricity markets have been developed in recent years in several European countries including Switzerland, Germany, 
TABLE 2 Criteria for

hydropower in green electricity

certification worldwide.

(Source: Markard et al. (2000))

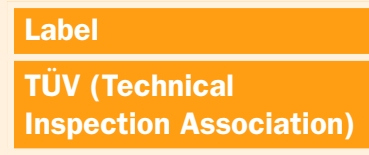

Future Energy
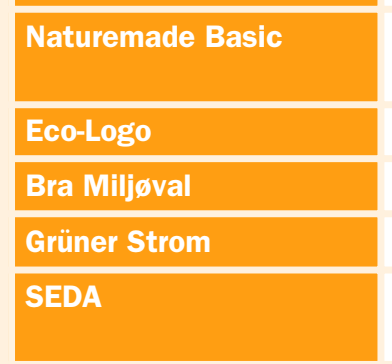

EnergieVision

(Öko-Institut)

Green-e

Naturemade Star

\begin{tabular}{|l|l|}
\hline Country & Type \\
\hline Germany & Declaration \\
\hline
\end{tabular}

UK Declaration

Switzerland Declaration

Canada Ecolabel

Sweden

Germany

Australia

Germany

USA

Ecolabel

Ecolabel

Ecolabel

Ecolabel

Ecolabel

Switzerland

\section{Criteria}

No criteria (different guidelines; two guidelines require that $25 \%$ of power supply must be from new plants)

Plants > $10 \mathrm{MW}$ and < 1990 only allowed for less than $50 \%$ of a product's supply

ISO 14,000 or EMAS certification if plant exceeds $10 \mathrm{MW}$; additional support for new renewables required

$<20 \mathrm{MW}$, no reservoirs

$<1995$

$<10 \mathrm{MW}$

No new dams, no redirection of water from one river to another, adequate environmental flows

No new dams, only improvement and reactivation, new construction work only for run-of-river plants

Low impact hydro standard, run-of-river plants only (formerly < $30 \mathrm{MW}$ )

Global and locally adapted criteria the Netherlands, and the United Kingdom. Many product declaration and ecolabeling schemes are in place worldwide to support the marketing of green electricity products, with different strategies on the use of hydropower (see Table 2).

The most widespread approach is applying a single criterion to keep procedures as simple as possible. The German Grüner Strom label, eg, is awarded to hydropower plants smaller than $10 \mathrm{MW}$, exclusively. The assumption is that small hydropower plants are not profitable and therefore require support. Canada's EcoLogo applies a capacity limit of $20 \mathrm{MW}$ for run-of-river plants, while reservoirs are excluded from certification. The Swedish Bra Miljøval label certifies all existing hydropower facilities in operation prior to 1995. Swedish environmental organizations wanted to inhibit incentives in the green electricity market for new hydropower plants. The German TÜV (Technical Inspection Association) generally accepts all hydropower plants. The Swiss Naturemade Basic label is similar in this regard but calls for implementation of an environmental management system.

The criteria mentioned so far for determining green hydropower are essentially meaningless from an environmental perspective. Neither the date of construc- tion nor installed capacity are indicators for assessing the local environmental impacts of a power plant. Sooner or later, these criteria will create considerable uncertainty among consumers when negative examples of certified hydropower plants are discussed publicly.

\section{Evaluating the ecological performance of hydropower}

A balanced approach based on the environmental costs and benefits of hydropower must address the problem of ambivalence. Electricity from hydropower plants creates no air pollution or nuclear waste and causes little $\mathrm{CO}_{2}$ or other greenhouse gas release. Furthermore, it is extremely energy efficient, and energy from storage plants is instantaneously available at the moment of demand. Nevertheless, the construction and operation of hydropower plants is also associated with local and regional impacts, some of which may be quite severe, including extinction of fish populations, loss of aquatic habitats, sinking ground water levels, deterioration of landscapes, etc.

This globally preferable but locally destructive energy system has considerable political relevance in many countries of the world. Its political implications are 
FIGURE 2 EAWAG's two-step approach to improving the ecological integrity of river systems that produce hydropower. (Diagram by authors)
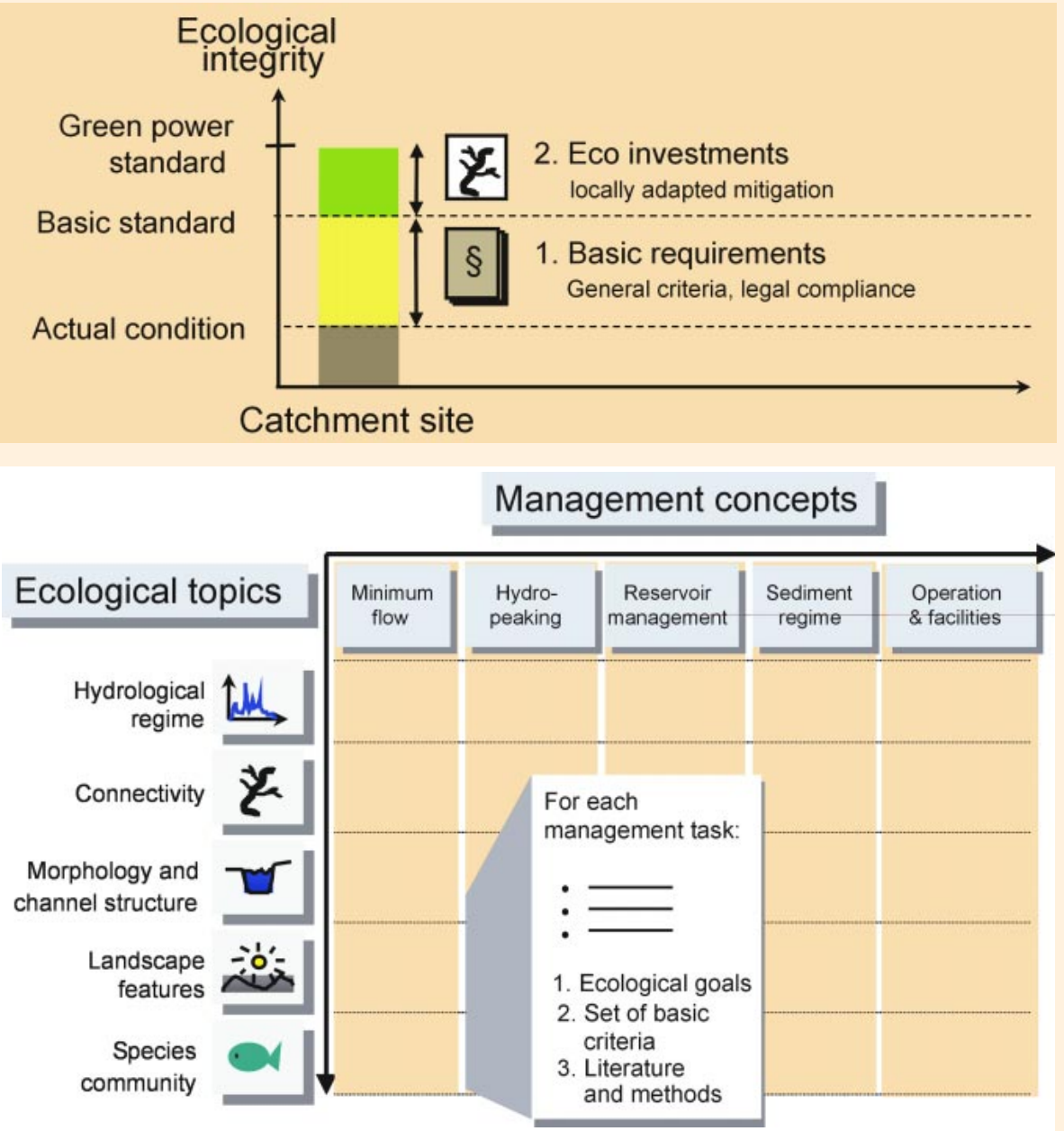

FIGURE 3 Basic criteria for green hydropower are formulated within a matrix of management concepts for hydropower operators, taking account of five different aspects of stream ecology. (Diagram by authors) quite extensive, especially in Alpine regions of central Europe, where most rivers have been dammed to produce hydropower. In Switzerland, eg, this situation caused deep division between environmental organizations and utility operators. But heated political debate about hydropower is not restricted to the Alpine mountain valleys of Switzerland. Free-flowing rivers are of major importance for ecosystem stability as well as human activities such as fishing and tourism. Furthermore, dried up rivers and massive concrete installations are highly visible and likely to provoke negative reactions. The environmental benefits of hydropower can therefore be easily questioned by critical stakeholders or media. Strategies to communicate the benefits of hydropower must deal actively with this public perception and sensitivity.
Only a few of the existing ecolabels address these issues. The American Greene label was first used in 1997 for run-of-river power plants with a capacity limitation of $30 \mathrm{MW}$. In light of negative experience, Green-e is about to drop the single-criterion approach and develop an encompassing set of criteria for green hydropower plants. Two other labels were devised to deal more adequately with the issue of hydropower from the outset. The Australian SEDA label and the EnergieVision scheme of the German Öko-Institut incorporate some criteria for local environmental impacts in their green hydro certification (Table 2). Finally, the Naturemade Star label applies a comprehensive assessment procedure for green hydropower recently developed by the Swiss Federal Institute for Environmental Science and Technology (EAWAG) as part of the Green Hydropower Project.

\section{A new environmental standard for green hydropower}

The leitmotif for the EAWAG project was to set up criteria that are (1) scientifically based and ecologically sound, (2) applicable in practice, and (3) locally adaptable.

Every single hydropower plant has unique local characteristics, making it difficult to improve ecological integrity. This has led to the development of a two-step approach involving basic requirements and ecoinvestments (see Figure 2). The basic requirements provide a common minimum standard for all types of power plants. They have a scientific basis and are designed to guarantee that no major environmental problem persists after the corresponding criteria are fulfilled. They represent a standard of good practice. In Switzerland, the basic requirements correspond approximately to the standard of a plant after it acquires a new license to operate according to current environmental laws. They therefore represent a science-based analog to legal compliance.

Beyond good practice and legal compliance, green hydropower producers must demonstrate added value through further environmental improvements. Ecoinvestments, the second step in Figure 2, were designed to allow for indi- 
vidually adapted improvements, which are set as a fixed mark-up on the kilowatthour. Ecoinvestments are of considerable use in public communication: hydropower plant operators may prove to their customers that their additional payments make a difference to the environment. In addition, ecoinvestments offer the flexibility to optimize local ecological performance beyond general criteria.

In order to assess the environmental impacts and qualities of a hydropower plant, a matrix approach was developed similar to the approaches used in industrial ecology (Figure 3). Assessment is based on five topics relevant to environmental impact analysis: (1) hydrological regime, (2) connectivity of aquatic systems, (3) morphology and sediment regime, (4) landscape, and (5) biotopes, including biodiversity. These topics were chosen from a review of the relevant literature, input from various experts in river ecology, and the results of a large-scale field study in the Blenio Valley in the southern Swiss Alps.

Methods for stream assessment, including analysis of changes in hydrology, river morphology, and biological indices based on the distribution and abundance of different organisms, are well established. The concept of lateral connectivity between rivers, riparian ecosystems, and lateral groundwater regimes has also gained wide acceptance. Assessing landscape characteristics such as the aesthetic appeal of waterfalls and rapids is a more qualitative endeavor. Criteria for these environmental domains are set by formulating requirements within the framework of five management concepts (Figure 3). The management concepts describe the design parameters for (1) minimum flow regime, (2) the mode of hydropeaking, (3) reservoir management, (4) sediment flushing, and (5) the specific operation and technology of the facilities. The full matrix outlined in Figure 3 defines the environmental goals, the basic criteria, and the methodological details in each of 25 fields.

Not all matrix elements are relevant to a given hydropower plant, however. In a pilot study, a potential green hydropower producer evaluates the priorities for environmental upgrading. Initial test cases have shown that only $10-15$ matrix elements with their basic criteria are relevant to a typical power plant. Some aspects of the main management issues are illustrat-
FIGURE 4 Minimum flow: Diversion of the River Inn in the Engadin Valley, eastern

Switzerland. The need for ecological upgrading of the minimum flow regime is evident in many places throughout the 23 Alps. (Photo by B. Wehrli)

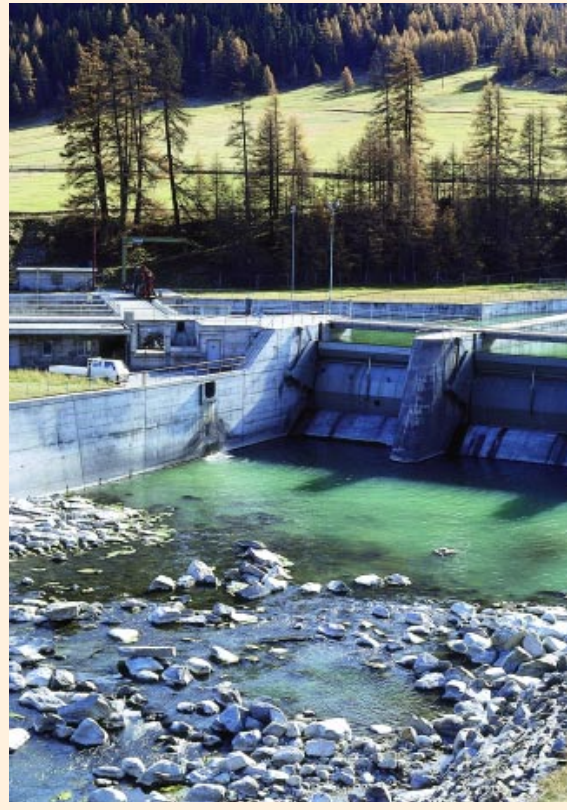

FIGURE 5 Hydropeaking: Gorge of the River Rhine near Versam. River banks and riparian vegetation are important habitats for many forms of life. They are highly vulnerable to hydropeaking, ie, sudden changes in runoff due to sudden opening and closing of the sluices used by hydropower plants with storage reservoirs. (Photo by B. Wehrli)

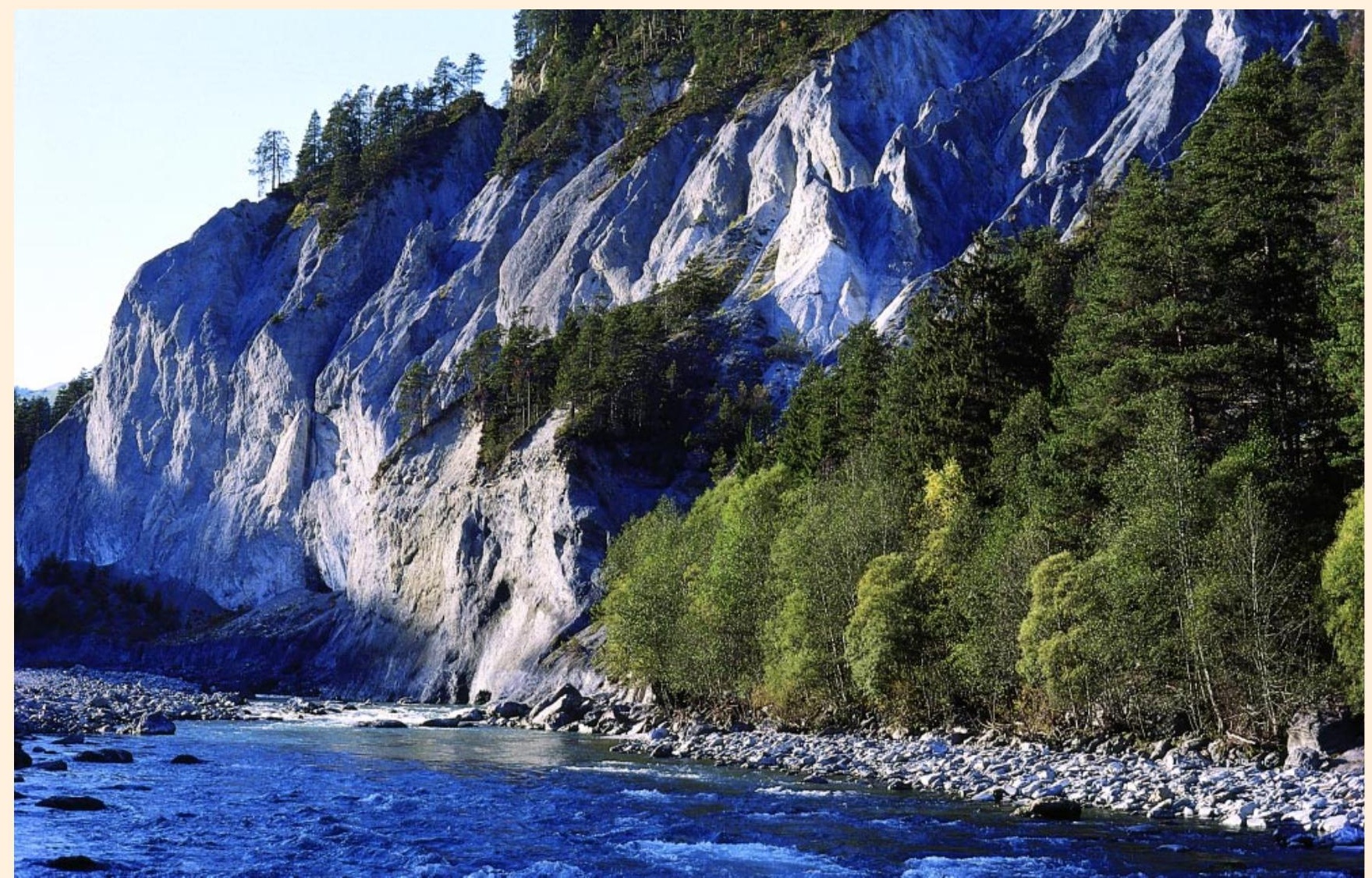




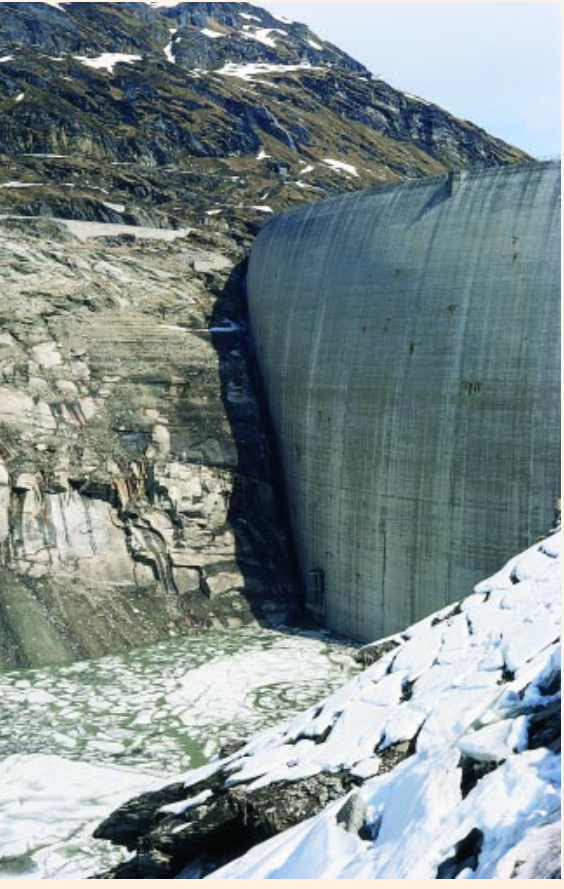

FIGURE 6 Reservoir management and sediment flushing: The Zervreila dam (Switzerland) was completely emptied for maintenance work in the 1980s. Careful procedures must be followed in operations such as this as well as in periodic flushing to remove sediment in order to minimize downstream ecological impacts. (Photo by B. Wehrli)

\section{FURTHER READING}

Gleick PH. 1998. The World's Water 1998-1999. Washington, DC: Island Press.

Graedel TE, Allenby BR. 1995. Industrial Ecology. Englewood Cliffs, NJ: Prentice Hall.

Karr JR, Chu E. 1998. Restoring Life in Running Waters, Better Biological Monitoring. Washington, DC: Island Press. Markard J, Truffer B, Bratrich C. 2000.

Ecological and competitive! Green electricity from certified hydropower plants in liberalized electricity markets. Proceedings of the International Hydro 2000 Conference, Berne, October 1-4. Sutton Surrey, UK: Aquamedia International, pp 717-727. Stanford J, et al. 1996. A general protocol for restoration of regulated rivers. Research and Management 12:391-413. ed in Figures 4 to 7 . This set of scientific criteria for the certification of green hydropower has the advantage of a method that is more or less independent of national legislation. More details can be found in the literature and on our web site (http://www.oekostrom.eawag.ch).

\section{Outlook}

At the end of 1999, a private, nonprofit organization was founded to develop a broadly accepted standard of quality for green electricity in Switzerland. The EAWAG assessment is used for certification of the Naturemade Star label. The first certified products are expected to be on the market by the end of 2000. Customer response will show whether the concept of green hydropower can establish a new, broadly accepted ecological standard.

In the long run, we hope that our science-based assessment will also help improve the design of new power plants and the upgrading of old ones outside Europe. Mountain regions in different parts of the world could thus learn from European economic and ecological experience with the liberalization of electricity markets.

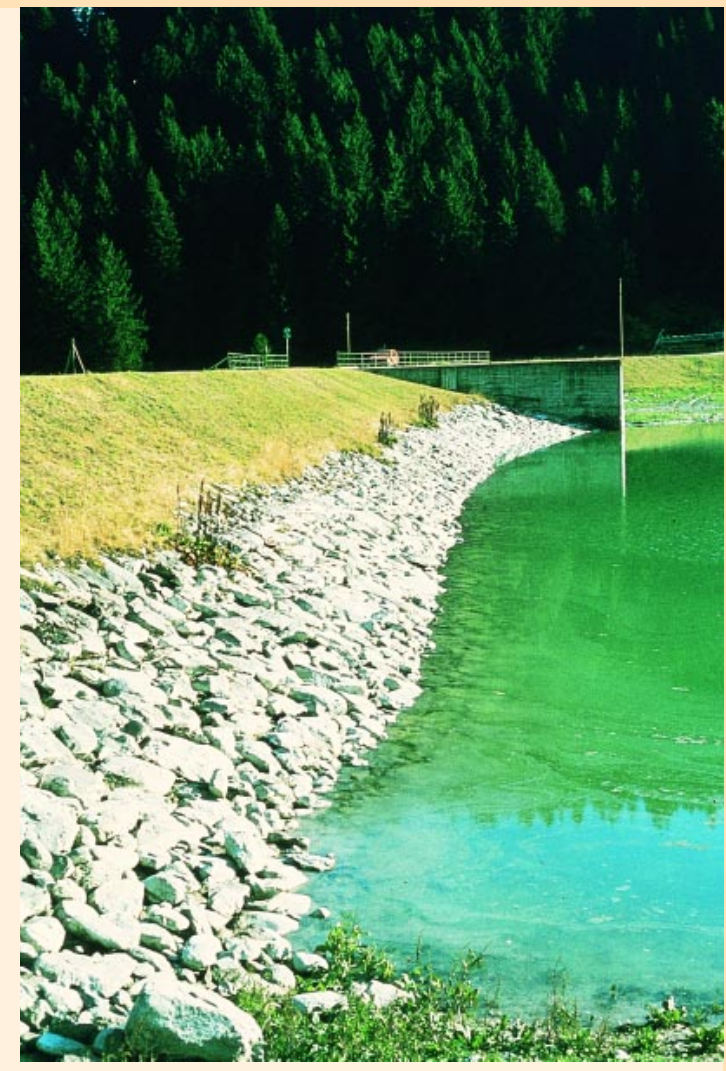

FIGURE 7 Environmental improvement for hydropower production and operation: This highly artificial shoreline at a small-scale hydropower reservoir near Brigels in eastern Switzerland (Rhine Valley) illustrates the potential for ecological improvement of many hydropower plants.

Revitalizing surface waters could both improve habitat quality for aquatic forms of life and enhance aesthetic appeal to tourists. (Photo by B. Wehrli)

\section{AUTHORS}

\section{All authors}

Limnological Research Center, Swiss Federal Institute for Environmental Science and Technology (EAWAG), CH6047 Kastanienbaum, Switzerland.

oekostrom@eawag.ch;

web site: http://www.oekostrom.eawag.ch

\section{Bernhard Truffer}

Bernhard Truffer has a PhD in social and economic geography from the University of Fribourg (Switzerland). Since 1993, he has been working as a social scientist at EAWAG. His special research interest is in energy (transport, electricity), with a particular focus on sociotechnical innovation studies. Since 1997, he has been the initiator and project manager of the transdisciplinary research green hydropower project at EAWAG.

\section{Jochen Markard}

Jochen Markard has a degree in electrical engineering and energy economics. At EAWAG, he is responsible for the Market and Policy Group in EAWAG's green hydropower project. He has been working on the issue of electricity market liberalization and green power since 1997.
From 1998 to 1999, he was employed by the Department of Project Management at MVV Energie AG, a municipal utility in Mannheim (Germany).

\section{Christine Bratrich}

Christine Bratrich has a degree in biology. From 1995 to 1996, she was involved in project work on integrated water management at the Institute of Zoology, University of Hohenheim (Germany). Since 1997, she has been a scientific collaborator and head of the Assessment Group of the green hydropower project at EAWAG. Her PhD research is on "Ecological Assessment and Decision-Making in Integrated Water Management."

\section{Bernhard Wehrli}

Bernhard Wehrli is Professor of Aquatic Chemistry at the Swiss Federal Institute of Technology (ETH) and head of the Department of Surface Waters at EAWAG. His research interests are in biogeochemical cycles of aquatic systems and the environmental restoration of degraded surface waters. He is coproject leader of EAWAG's green hydropower project. 